\title{
Contextualized IT Education in Tanzania: Beyond Standard IT Curricula
}

\author{
Matti Tedre, Nicholas Bangu, and Seth I. Nyagava \\ Tumaini University, Iringa, Tanzania
}

\section{matti.tedre@tumaini.ac.tz; nicholas.bangu@tumaini.ac.tz; seth.nyagava@tumaini.ac.tz \\ Executive Summary}

Tumaini University at Iringa, Tanzania, started a new B.Sc. program in IT in 2007. In the course of planning and implementation of the program, we found out that standard ACM/IEEE IT curricula are not adequate for an IT program in a poor, developing country. The standard curricula describe, in detail, the competences that IT specialists in industrialized countries should possess, but the special characteristics of developing countries require a plethora of additional skills and competences that IT professionals in developing countries should have.

The environment—natural, cultural, and technical—of developing countries brings about issues that IT specialists in industrialized countries do not know much about. Inadequate ICT and electrical infrastructure cause hardware to malfunction, wear out, and break; a hostile natural environment causes problems with equipment and eventually destroys it; quirks of local manufacturing and procurement complicate acquisitions; counterfeit products, inexistent customer care, and lack of warranty make purchases risky; excessively complex customs and shipping procedures make foreign acquisitions painful; widespread problems with corruption make accounting tricky; and lack of qualified staff is a systemic problem.

In industrialized countries there is a high level of specialization and separation of professionals and their tasks, and one can easily delegate parts of a project to consultants. But in Tanzaniaespecially in rural Tanzania - there usually are no specialists available. IT professionals have to be able to do a large number of rudimentary tasks outside the field of IT. The most common tasks concern electrical installations, telephony, architectural design, structural modifications to buildings, protection from forces of nature, and all kinds of installation-related construction tasks.

In an attempt to make IT education in our university relevant to the local environment and socioeconomic context, we have pinpointed four areas of IT curriculum that we have had to re-think. Firstly, the pedagogical approach must resonate with students' and teachers' learning styles. Secondly, the scope of IT education must be broader than the scope of IT education in industrialized countries. Thirdly, selection and emphasis of topics must meet the needs of Tanzanian soci-

Material published as part of this publication, either on-line or in print, is copyrighted by the Informing Science Institute. Permission to make digital or paper copy of part or all of these works for personal or classroom use is granted without fee provided that the copies are not made or distributed for profit or commercial advantage AND that copies 1) bear this notice in full and 2) give the full citation on the first page. It is permissible to abstract these works so long as credit is given. To copy in all other cases or to republish or to post on a server or to redistribute to lists requires specific permission and payment of a fee. Contact publisher@informingscience.org to request redistribution permission. ety. Fourthly, all kinds of cultural, technical, environmental, and other contextual issues must be understood and taken into account in curriculum and course design.

Keywords: IT, information technology education, developing countries, Tanzania, curriculum development, contextualization. 


\section{Introduction}

Tanzania's first computer was imported and installed in 1965, and roughly ten years after there were seven computers in the country (Mgaya, 1994). However, computing projects during those years invariably failed. Klodwig Mgaya, who is one of the pioneers of computing in Tanzania, argued that there were several reasons for those failures (Mgaya, 1994). Firstly, the computing installations were not run by Tanzanian staff but by foreign experts, and, as the experts left the country, the installations started to fail. Secondly, uncoordinated planning and lack of contextual understanding led to collapses of major governmental projects. Thirdly, despite whatever computing competence there might have been, in 1974 the government imposed a ban on importing computers, which effectively halted any further attempts to develop computing in Tanzania.

The Ministry of Education in Tanzania holds a centralized control of all matters of education, which makes the educational system unnecessarily rigid (Mgaya, 1994). Although computing education was started already in 1965, and although M.Sc. courses in computing were started in the University of Dar es Salaam in 1974, by the year 1984 only 12 Tanzanians had received a M.Sc. degree in computing from Tanzanian institutions. Mgaya (1994) attributed several reasons to the failure of IT (Information Technology) education in Tanzania. Firstly, in the early years of development of Tanzania's electronic computing, the misguided policies, banning of computer imports, and unwillingness to invest in computing training led to major failures of implementation, which, for its part, caused pessimism towards computing among general public. Secondly, even today there are few computing professionals and even fewer computing instructors. Third, books and journals are costly for Tanzanian educational institutions. Fourth, hardware is much more expensive in Tanzania than, for example, in the U.S. - both in absolute and in relative terms. The Tanzanian National ICT (Information and Communication Technology) Policy from 2003 explicitly notes the shortage of qualified IT professionals in the country (Ministry of Communications and Transport, 2003, 2.2.3).

So, a number of imported, theoretically oriented computing curricula have failed to meet expectations. That same problem seems endemic to the country's educational system: several universities offer theoretical education in fields such as agriculture and civil engineering, yet no locally organized major improvements of agriculture have been made since the 1960s, and most civil engineering project tenders are won by Asian or European companies. To avoid similar failures in the future, in addition to theoretical knowledge, Tanzanian higher education should focus on developing students' practical skills. Students should not only know what to do but also how to do it. IT graduates should have the ability to use, manage, evaluate, and understand modern IT tools (e.g., ITEA, 2007, p. 9).

In Tanzania, ICT infrastructure is not well developed. There is no Internet backbone but a number of unconnected systems owned by various companies. The power-distribution network is sparse and unreliable, and in many places the power network and transformers work at the limits of their capacity. Landline communications network is very sparse, and also the mobile phone network is far from being extensive. Building contractors and electricians are ignorant of infrastructure requirements of modern computing and communications equipment. And unlike in industrialized countries, one cannot rely on an extensive network of experts who can be called to take care of problems in technical, specialized fields. Because there are few experts, Tanzanian IT graduates must have a broad education. They must be able to solve basic problems on-site: problems regarding, for instance, electricity, building design, electrical interference, taxes and duties, and procurement.

In order to educate broadly trained professionals, Tumaini University launched a new B.Sc. program in Information Technology (hereafter also BSC-IT program) in September 2007. A significant amount of work was done in order to refine the curriculum so as to contextualize it to the 
needs of Tanzania (e.g., Bangu et al., 2007; Islas, Vesisenaho, Tedre, \& Sutinen, 2006; Lund, Nielsen, Sutinen, \& Vesisenaho, 2005; Sutinen \& Vesisenaho, 2006; Vesisenaho, 2007; Vesisenaho, Duveskog, Laisser, \& Sutinen, 2006; Vesisenaho, Kemppainen, Islas Sedano, Tedre, \& Sutinen, 2006). The new curriculum was based on six principles (Bangu et al., 2007), which were designed to promote teaching that was context-sensitive, based on problem-solving projects, oriented strongly towards practice and activity, interdisciplinary in design and implementation (Computer Science (CS) and Engineering being the other fields of study that were incorporated), of the standard that would be internationally recognized, and based on research. That curriculum did not, however, explicitly touch on the core IT skills necessary in Tanzania, nor how those core IT skills should be considered in the curriculum.

A concern about lack of skills concerns many areas of education. In early 2008, Tumaini University's administration launched an initiative that was aimed at developing all Tumaini's academic programs to incorporate skills training in their curricula and pedagogy. The administration's concern was that if graduates of Tumaini's programs did not have the skills needed for their future professions, Tanzania would remain dependent on foreign experts for decades to come. To answer the administration's call, the IT directorate rose up to the task and went on to develop the practical skills part of the BSC-IT program. This article describes how skills are incorporated in Tumaini's curriculum. A skills-oriented curriculum in a developing country has to be adapted to the environmental, sociocultural, educational, and technological realities of the country. Hence, the curricular and pedagogical choices in Tumaini's IT program differ slightly from those in industrialized countries.

This article is aimed at two kinds of audience. First, this article is aimed at administrators, curriculum designers, and IT educators who wish to undertake similar tasks or similar programs. Second, this article is aimed at IT educators or other people interested in the special characteristics of information technology education in developing countries. This article shows how, and why, standard ACM/IEEE information technology curricula are inadequate for many developing countries; and this article shows how those inadequacies can be taken into account in curriculum design.

\section{Information Technology and Other Fields of Computing}

In industrialized countries, the field of computing is divided into a number of specific subfields, each of which is concerned with some specific issues. Disciplinary boundaries of computing are notoriously vague, as there are a plethora of different branches of computing, but the standard, generic definitions are as follows. Electrical engineering provides the foundations for computer engineering, and it deals predominantly with hardware. Computer science studies the theoretical foundations of automatic computation and the implementation of computing systems. Computer engineering stands between computer science and electrical engineering, and it incorporates elements from both. Software engineering focuses explicitly on the systematic principles of producing software. The field of information systems deals with the development, implementation, and study of information flows and information processing systems in organizations and society at large. Finally, the Information Technology Association of America defined information technology as "the study, design, development, implementation, support or management of computerbased information systems, particularly software applications and computer hardware”. Figure 1 portrays one view of the relationship between these fields. 
Information technology, with its service bent, practical orientation, and technological focus, is more useful for the current Tanzanian context than the other fields in Figure 1. Computer science, software engineering, and information systems require robust, secure, and appropriate infrastructure to run on, and in Tanzania that infrastructure is still largely undeveloped. Electrical engineering and computer engineering, on the other hand, downplay a service orientation towards serving the needs of society and organizations. Indeed, it has been argued that "IT programs exist to produce graduates who possess the right combination of knowledge and practical, hands-on expertise to take care of both an organization's information technology infrastructure and the people who use it" (SIGITE Curriculum Committee, 2005, p. 14). Certainly, this is what is needed in a developing country where both infrastructure and computer literacy skills are lacking.

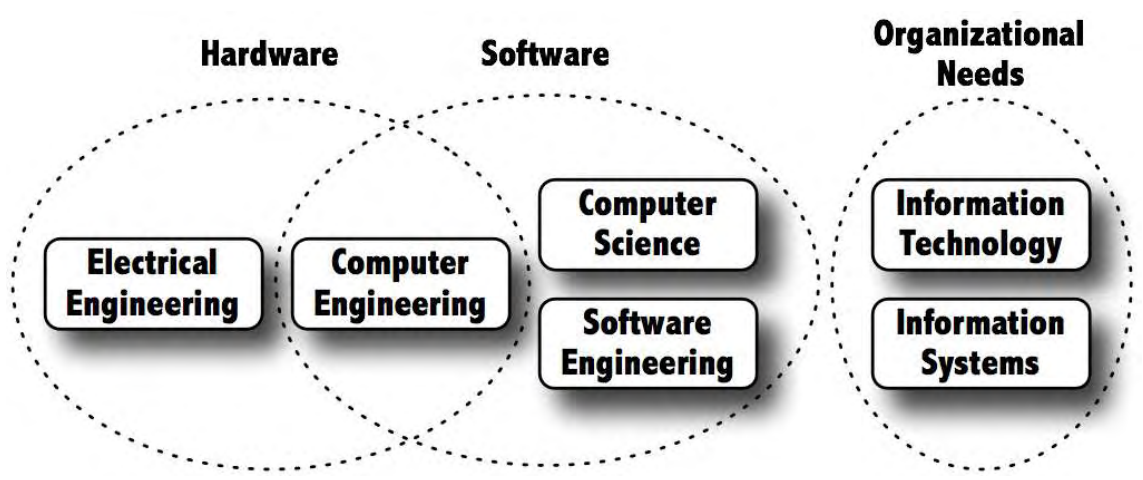

Figure 1: Computing Disciplines and Their Principal Foci (SIGITE Curriculum Committee, 2005, p. 14)

Although IT programs offered in different institutions differ more from each other than, for instance, information systems programs, IT programs are still a uniform enough group to distinguish them from computer science programs or information systems programs (Reichgelt et al., 2004). The ACM SIGITE final report on their project on B.Sc. programs in IT has become a definite guideline for IT curriculum design (SIGITE Curriculum Committee, 2005). That document portrays an image of IT as a field distinct from other computing fields; the document identifies the IT body of knowledge, portrays a set of learning outcomes in IT body of knowledge, defines the core IT material as well as elective courses, identifies four curriculum models, and describes a number of courses in IT. But although the standard ACM IT curriculum might be directly applicable in industrialized countries, usually developing countries are a very different setting. A somewhat contextualized approach is usually necessary for IT education in developing countries.

\section{IT Education at Tumaini University}

Tumaini University is a private, Christian university operated by the Evangelical Lutheran Church of Tanzania. Tumaini University has six campuses in Tanzania, and the biggest of those six campuses is Iringa University College (IUCo) at Iringa town (capital of Iringa region.) Iringa is located in a rural and mountainous area about $502 \mathrm{~km}$ (312 mi) west from Dar es Salaam; the main source of income in the area is agriculture.

The college has around 3000 students with a roughly equal male/female ratio. Students come from all around Tanzania and neighboring countries (e.g., Zimbabwe, Uganda, and Kenya), and the student profile reflects the variety of cultural backgrounds in sub-Saharan Africa (in terms of, e.g., religion, nationality, ethnicity, and tribe) (Sutinen \& Vesisenaho, 2006). The college also attracts some foreign exchange students each semester. 
The college's IT services and IT education have been developed systematically from very early on: first by Western volunteers, from 1998 until 2007 by Western IT experts working on a fixed term basis and assisted by Tanzanian IT support staff, and from 2007 by a permanently appointed Tanzanian IT expert, who has a four-year degree from a European polytechnic school. The number of computers has grown from 18 computers in 1999 to the current number of 308 computers, and computing technology is today used extensively for teaching, administration, student work, and capacity building.

Following several years of program planning, Tumaini University launched a B.Sc. program in IT in September 2007. The student intake in 2007 was 27 students and in 2008 it was 30 students, some of whom applied directly to the BSC-IT program while some others transferred from other programs, such as business administration and mathematics education.

\section{Tumaini's BSC-IT Program Principles}

Tumaini's BSC-IT program is based on six principles that have from the beginning steered the development of the program curriculum (Bangu et al., 2007.) The first principle, contextsensitivity, refers to the idea that each society, climate, environment, economy, and culture pose some unique challenges for IT professionals, and that local IT curricula should respond to those challenges. Various issues of context-sensitivity will be further illustrated later in this article. The second principle, problem orientation, refers to the typical constructivist approach of problembased and project-based learning - that is, students work on authentic problems and reflect on the experiences they gain while working on those projects.

The third principle, practicality, refers to the idea that in Tanzania, IT professionals face all kinds of practical and theoretical issues, and without practical training the graduates may not be able to work with the various hands-on tasks that are expected of them. The fourth principle, interdisciplinarity, refers to the combination of information technology (IT) curricula, computer science (CS) curricula, and computer engineering (CE) curricula; as well as to the need to incorporate subject areas such as development studies and business in the IT degree curriculum. IT professionals must have the ability to work with people from various fields.

The fifth principle, international recognition, refers to the fact that in order for graduates to work in countries other than Tanzania and to continue their studies in international master's level programs, the program must conform to the international standards of IEEE and ACM (e.g., ACM, 2001; SIGITE, 2005). The sixth principle, basis on research, refers to the need to develop the curriculum further, and to base any revisions of the curriculum on rigorous research on-site.

A research-based curriculum that is based on formative development faces a number of challenges that might not be unique to Tanzania or to Africa. The challenges begin at home. The Tanzanian educational system has traditionally been unreceptive to feedback from students, and not all the teachers are responsive to students' course evaluations or critical learning diaries. Such attitudes of teachers might be explained by the oppressive character of the teachers' own education, where students were considered ignorant, and the professor was the best source of knowledge (e.g., Freire, 1970, p. 28, 45). Another challenge is that not all the lecturers are familiar with e-learning tools or e-pedagogy, which creates additional difficulty as teachers as well as each new cohort of students are unfamiliar with modern e-learning.

In our curriculum design, we did not consider the fact that not everyone shares the same ideas about concepts that are very abstract (e.g., context sensitivity, problem-based learning, and practicality) (Tedre, Sutinen, Ngumbuke, \& Bangu, 2008). That is, it was implicitly assumed that tutorial assistants, Tanzanian students, program designers, program management, university administration, and all other stakeholders would all share the same idea about the essence, importance, and implications of, say, 'practical orientation.' That implicit assumption indeed ran 
against the very idea of contextual understanding. But in reality, students had their idea of what 'practical' means, tutorial assistants (graduates of a theoretical program in the University of Dar es Salaam) had their idea of what 'practical' means, and surely program designers, university management, and other stakeholders all had their own views on what 'practical' actually means. For instance, some students considered practical orientation to mean hands-on classes, some teachers considered practical orientation to mean homework ('practice') in theoretical subjects, and external stakeholders considered practical to mean field trips and outreach projects.

Furthermore, there are sometimes clashes between students' demands for practical sessions and teachers' insistence on conceptual lecture-based learning. Practical classes are often difficult to arrange due to the resources they require. Due to the rapid growth of the college, there is an acute shortage of office space, and hence there is no workshop room available. Due to lack of money there is not enough equipment to set up a network lab or a hardware lab. When it comes to staff, there is a much higher turnover of workers than in universities in industrialized countries-some go abroad for studies, some undertake diploma or certificate studies in Tanzania, some change jobs, and some get fired. Staffing is a continuous and acute problem. These challenges are not quickly addressed, and there are no quick solutions for overcoming them (Tedre et al., 2008).

\section{Pedagogical Concerns}

A great number of things that are usually not a concern in industrialized countries-such as extreme poverty, the post-colonial condition, and tribal traditions-affect the pedagogical approach in Tanzania. Tanzanian students come from a great variety of religions, tribes, and cultures, which make it nigh impossible to find a "fit-for-all" pedagogy (and one might doubt whether that is even desirable). Very different kinds of views of ethics, debate, and modes of working, as well as different linguistic backgrounds, create diversity in Tumaini’s programs.

The various cultures of Tumaini's students offer great possibilities for the BSC-IT program. Most of the cultural differences can be harnessed to support students and the program, and there are a great many phenomena that educators in industrialized countries would desire to import to their own institutions - such as students' will to help each other in all things possible, their dedication to their studies, and their unity in front of problems. Of course, there are also some ideas and things that we would like to bring to Tanzania from the industrialized countries-things such as emphasis on critical reading skills, individual working skills, and life-long learning.

In a program where students and teachers have various cultural backgrounds there are a number of strategies and attitudes that teachers can embrace to support inclusive and multiperspectival learning. Cultural sensitivity, empathizing with students, respecting students, and attempting to understand the students' situation are key elements among those strategies (e.g., Fielstein \& Phelps, 2001, pp. 95-96). Moreover, in a post-colonial context, education also has to play a liberating role: an education must be detached from its role of turning students into "containers" that the teacher is supposed to fill with knowledge (Freire, 1970, p. 53). Education that is not aimed at maintaining oppressive attitudes and practices must pose problems, embody true communication and dialogue, resolve the student-teacher contradiction, encourage critical thinking, stimulate reflection, and take the students' historicity as a starting point (Freire, 1970, pp. 60-65).

Today Africa's educational system is a mixture of Western education, Islamic education, and African traditional education (Farrant, 1981, p. 34). These different educational traditions cause challenges to constructivist learning. One of the challenges of constructivist learning comes from the fact that often students' previous education has relied on rote memorizing, and individual learning initiatives have not been encouraged. Hence, many students do not trust that they are capable of finding information and coming up with answers or solutions themselves. That leads to challenges with independent work. In addition to lack of confidence, African communalism 
discourages students from struggling alone with their tasks. Although communalism may arise from poverty and struggle, a deep-rooted communalist culture of sharing and helping other extended family members at home is a great source of a dynamic culture of sharing and collaborating in academia also (e.g., Farrant, 1981, p. 31). Farrant (1981, p. 31) argued that the communalist tradition in Africa is seen in "how it inspires co-operation between individuals, not competition; how it copes with crises by marshalling the resources of the community to help those in trouble; and how, in major challenges, it claims united action.” Backhouse (2005) even argued that utilizing "the strong listening skills and conflict resolution skills among African students"an African style of group work - in software design may help to produce better software.

Farrant's (1981, p. 31) notion of communalism in school is supported by independent studies conducted at Tumaini. Larsen and Loft Rasmussen (2008, p. 51) reported that Tumaini's IT students collaborate through group discussions, doing assignments together, and explaining lectures and concepts to each other. Teachers in the BSC-IT program have found out that collaboration is a much more productive motivator than competition is. In line with Farrant's (1981, p. 31) argument, Tumaini's IT students often unite when they demand change. Some clashes arise, however, from the students' views on, for instance, curriculum and collaboration, and the teachers' view on curriculum and collaboration.

Because students have been systematically involved in curricular decision making, their views are heard even when the students do not, strictly speaking, know enough about the issues at stake. For instance, instead of using Microsoft Access for learning the basics of databases, students strongly demanded to use Oracle products or MySQL; what they refused to appreciate was that platform choice is largely irrelevant for learning the key concepts about databases. When it comes to collaboration, there is a difference between the views of teachers and students. Whereas students perceive only the benefits of collaboration, teachers struggle with some of the (minor) side effects, such as plagiarism and copying home assignments from each other (Larsen \& Loft Rasmussen, 2008, pp. 58-59). Also, sometimes the students' tendency to stand united results in unpredictable and inconsistent behavior: for instance, students once united behind a strong student leader in vehement demands that their class arrangements must be changed, and only a few days afterwards they one by one started sending the program administration e-mails that the idea might not have been the best possible one.

Western educators have often, and in many ways, failed to understand that an educational system that works well in one context may be a profoundly disturbing force in another context (Farrant, 1981, p. 33). In his manifesto Pedagogy of the Oppressed Freire (1970, p. 75) argued that "[m]any political and educational plans have failed because their authors designed them according to their own personal views of reality, never once taking into account (except as mere objects of their actions) the men-in-a-situation [sic] to whom their program was ostensibly directed.” Pedagogical choices must not be derived from foreign, imported educational ideals, but they must arise from the local reality to form an indigenous, locally made pedagogy (e.g. Freire, 1970, p. 36). Imported pedagogy - which Freire (1970) characterized as cultural invasion — often fails to serve Africa's real needs (Farrant, 1981, p. 33); yet there are still educators in Africa who struggle to replicate the imported models (Farrant, 1981, p. 33). Farrant (1981, p. 39) argued that the key to successful African education is in an educational system that is truly national, democratic, modern, and authentically African. We do not know exactly what that pedagogy or educational system is, but we are aiming there by including BSC-IT students in pedagogical and curricular choices.

The problem for us is that replacing one imported learning theory and practice (instructionism and rote memorization) with another one (constructionism and problem-based learning) does not make the pedagogy any less imported. Nevertheless, due to the systemic lack of knowledge about indigenous pedagogical systems in Tanzania, we have chosen to start from a problem-based 
pedagogy and in the course of time adapt our pedagogy to give way to any pedagogical insights or practices that may arise in the classroom. Storytelling is one promising example of an African pedagogy, and we are currently working on tools and pedagogies for storytelling in academic environment. Furthermore, as we work between conflicting ideals and aims, some compromises have to be made. For instance, communalism (a truly local ideal and practice) has to sometimes give way to individual research and writing (imposed idea), because the graduates must be able to continue-individually - to further studies in foreign institutions. Creating a locally meaningful and authentically African educational program that prepares students for the global academic and industrial communities requires delicate balancing between high ideals and hard reality.

In the problem-based pedagogy of the BSC-IT program, students do a lot of hands-on work, which is aimed at learning that takes place simultaneously on the knowledge, comprehension, and application levels of the cognitive domain (cf. Bloom, Englehart, Furst, Hill, \& Krathwohl, 1956). Learning on the analysis, synthesis, and evaluation levels of the cognitive domain is addressed by, for instance, critical reading assignments, student reviews of their own work and their peers' work, integrative projects (e.g., courses Application Project I \& II) that bring together knowledge from several curricular subjects, real-world activities with customers from Iringa (e.g., work with non-governmental organization (NGO) Global Outreach), and interdisciplinary projects between BSC-IT program and other faculties (e.g., a project undertaken to create a tourism and information web site on Iringa.)

From a theoretical point of view, the pedagogy of the program has a slight social reconstructionist flavor, as students are encouraged to find social issues and seek to find ways ICT can help to address those issues. The BSC-IT program is constantly working on community development projects; for instance, the program collaborates with NGOs, such as Global Outreach and Research Technology Associates, whose aim is to bring Internet labs to Tanzanian schools and to educate students to use computer technology for their studies. Students in Tumaini's BSC-IT program participate in the installation and maintenance of those labs, as well as in a number of educational and promotional activities.

In the end, as students in Tumaini's BSC-IT program make significant financial and social sacrifices for their education (e.g., they move away from their families for three years and they take bank loans worth around four times the average annual gross domestic product (GDP) per capita), they are extremely motivated in their studies, and the only open question for educators is to find ways of harnessing that motivation for the best possible learning.

\section{Theory and Practice}

The tension between the principles of international recognition and practicality in Tumaini's IT curriculum poses some special challenges to curriculum design. Yet, those challenges are perceived in the computing community at large-in fact, the tension between theory and practice has haunted computing disciplines ever since the birth of modern computing (Tedre, 2006, pp. 283286). Theory is indeed the bedrock of academic computing - any academic curriculum in IT must have a sound theoretical base (Denning et al., 1989). But there again, without design and implementation of technological tools, computing would be just idle speculation (Hamming, 1969). Although all IT professionals must know some theory of computing, they should not forget about the users and their real problems (Brooks, 1996).

Dawson and Newman (2002) noted that the tension between theory and practice is especially strong in the field of IT, where new fashions and fads can appear, flourish, and disappear within a few years. Deeply theoretical topics in IT are more stable than specific technical topics, but IT students must be able to work effectively in their field after their graduation, and that requires knowledge of tools. Then again, there are specific tools and there are the principles of tools, and 
teaching the latter is much more meaningful than teaching the former. The different aspects of theory and practice are often called, for instance, formal science, pure science, applied science, engineering, and technology (e.g. Tedre, 2008; Vincenti, 1990). In this article that discussion is elided, but it should be noted that in computing those different aspects are deeply intertwined (e.g. Denning et al., 1989).

In their overview of different curricula in the field of computing (computer engineering, computer science, information systems, information technology, and software engineering), the SIGITE Curriculum Committee (2005, pp. 15-21) considered the problem areas in which practitioners of each computing discipline typically work after their graduation. In the committee's original picture (SIGITE Curriculum Committee, 2005, p. 20), the problem field of IT practitioners covers the applied sides of organizational issues, application technologies, software methods and technologies, and systems infrastructure (see the dotted line in Figure 2).

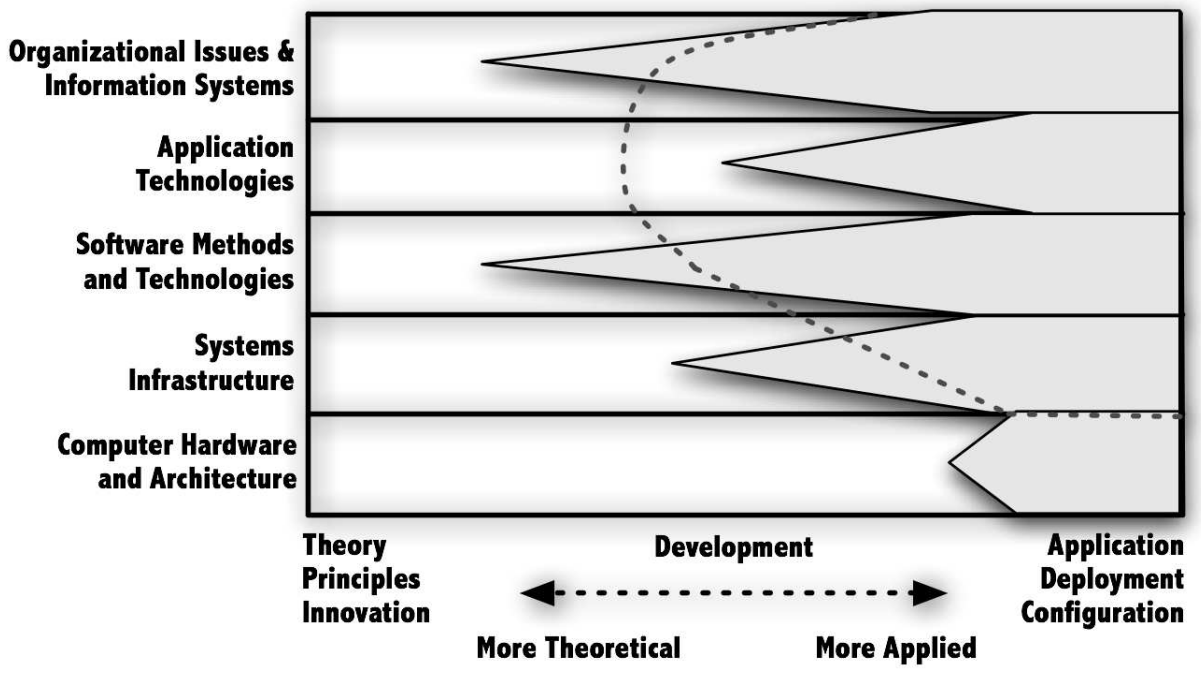

Figure 2: Problem Space of IT in Tanzania

In Tanzania the problem space, within which IT professionals work, is similar to SIGITE Curriculum Committee's (2005) description. IT professionals work with application, deployment, configuration, and troubleshooting-related needs of clients. However, in the areas of organizational issues and information systems, as well as in software methods and technologies, IT professionals must be able to shift from technē and lower levels of the cognitive domain to higher levels of the cognitive domain — analysis, evaluation, and synthesis. That shift requires theoretical knowledge, conceptual foundations, and understanding of the principles of the topics. It is not, however, easy to mix practical and theoretical aspects in a curriculum.

In our curriculum, the term theoretical courses does not refer to courses that employ only formal or analytical methods, nor does the term stand in binary opposition to practical courses. Theoretical courses are courses that emphasize theoretical learning, analytical skills, and conceptual knowledge. The term practical courses refers to courses that emphasize lab work, practical sessions, hands-on projects, and skills development. We have approached the theoretical/practical division by alternating between practical and theoretical learning, as well as by blending them.

In practical courses, the emphasized method of working is the (technological) design process (Denning et al., 1989), which begins with identifying, analyzing, and defining the issue-a problem or possibility that arises in the course of people's life. That is, students have to understand the problem, issue, or possibility clearly (ITEA, 2007, p. 6), and formulate a set of requirements concerning a working solution of the issue (Denning et al., 1989). Then students generate a num- 
ber of alternative solutions and choose one or more of the most promising solutions to be implemented (ITEA, 2007, p. 6). Students design and implement a working solution and, if necessary, change the design (ITEA, 2007, p. 6; Denning et al., 1989); finally students test their solution. After a series of iterations of this process, students arrive at the final outcome-a tool, innovation, or piece of software that helps with the original issue.

We have not blended theory and practice in every course. Some of the courses are theoretical, some are practical, and some blend theory and practice. Donald Knuth (1991) noted that "Theory and practice are not just two sides of the same coin. They deserve to be mixed and blended, but sometimes they also need to be pure.” In the BSC-IT curriculum, theoretical and practical courses also alternate. Theoretical courses prepare students by giving them conceptual and theoretical understanding of the field, and in practical courses students can take that understanding into authentic uses. In practical courses students are required to reflect on the relationship between their practical work and what they have learned in their classes. Practical courses are not, however, intended to be the end of the cycle, but they are intended to provide students with motivation and orientation for their theoretical courses.

\section{Syllabus}

Tumaini University's B.Sc. program in IT is a three-year program with two internship periods during vacations between the study years. The BSC-IT curriculum consists of 120 credit units in 35 courses. The amount of teaching in the courses range from 1.5 credit units to 6 credit units (1 credit unit involves 15 hours of lectures or practical sessions, plus homework). There is heavy emphasis on practical work in authentic setting: 18 credit units (15\% of the total number of credit units) come from internships. The syllabus, divided to six semesters, is portrayed in Figure 3. In Figure 3, the number of credit units per each course is denoted by the width of each rectangle. In addition, practically oriented courses are colored black, theoretically oriented courses are colored white, and courses that mix theory and practice are colored gray.

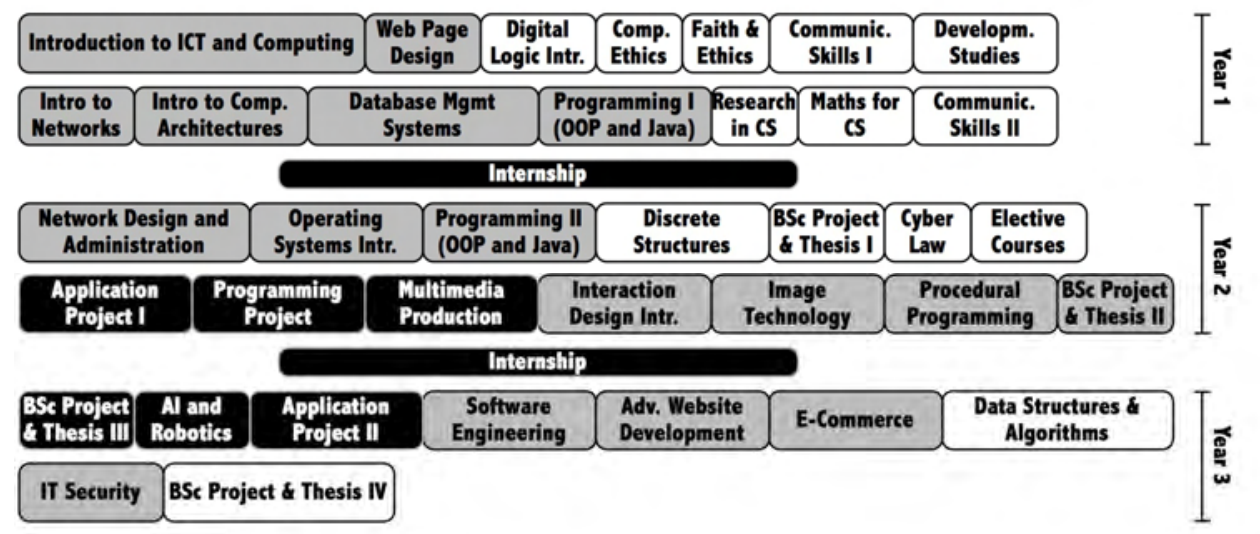

Figure 3: Syllabus of Tumaini's Three-Year B.Sc. Program in IT

Although the course listing in Figure 3 looks very similar to that in any country, course contents and pedagogical approach in Tumaini's BSC-IT program are different from most programs in industrialized countries. Take, for instance, a first-year "101” IT Fundamentals course taught in the U.S., as described by Aasheim, Lee, and Reichgelt (2006). The same 101 introductory course takes somewhat different form in Tumaini's BSC-IT program. The differences are due to several reasons. For example, the educational background of Tanzanian students is different from students in the U.S.; Tanzanian students' computer literacy level when entering higher education is close to zero, understanding of some fundamental aspects concerning digital technology—such as 
information security, basic functioning of electronic equipment, and account and password protection - is not yet there, and access to computing facilities and equipment for hands-on practice is very limited. Tumaini is a private university and Tumaini's students are from relatively welloff families, so a high number (approximately 38\%) of students have an access to computer at home, and $8 \%$ of students even have a home Internet connection (Tedre \& Chachage, 2008).

When they enter university, many Tanzanian students are unaware of many things that students in the U.S. learn already in K-2 to K-5 levels, such as the concepts of information, symbols, characters, icons, and computing and communication technology (ITEA, 2007, p. 168-169). K-6 to K12 concepts, such as input-process-output, digital-analog distinction, and encoder-transmitterreceiver-decoder (ITEA, 2007, p. 174) are usually unfamiliar for Tanzanian university students. Therefore the education of IT students must include some very generic technology education strands.

\section{Competences}

In a number of articles and curricula recommendations (e.g., Ekstrom et al., 2006; Reichgelt et al., 2004; SIGITE, 2005) one can find ten skills and capabilities that all IT graduates should possess:

1. Use and apply current technical concepts and practices in the core information technologies.

2. Analyze, identify and define requirements for addressing users' problems or opportunities.

3. Design and implement IT-based solutions using the state-of-the-art practices in the discipline.

4. Create and implement a project plan while adhering to resources like time and budget.

5. Identify and evaluate technologies and their applicability to solve users' needs.

6. Analyze the impact of technology on individuals, organizations and society.

7. Demonstrate independent critical thinking and problem solving skills.

8. Collaborate in teams to accomplish a common goal.

9. Communicate with clients and peers effectively, efficiently, and using proper terminology.

10. Recognize the need for continued learning.

The first six competences in the list above are usually found explicitly in course descriptions. The last four competences and skills, however, are often an implicit part of IT education. The first five competences in the list above are core technical and professional competences, which must be addressed explicitly in the curriculum. The last five are ethical and professional competences, which are of such importance that they must be interwoven into a number of courses. For instance, a course on e-Business should address ethical and legal issues, and project-based courses should address teamworking, communication, leadership, and problem-solving issues.

In our curriculum, we have defined five 'paths' that develop students' competency in five core technical/professional areas that are important in their work in Tanzania (or any other country for that matter) and in their academic career. Those core areas are software engineering (and programming), network administration, web application development, hardware support, and academic work. Our core areas are similar to the five pillars of IT curriculum as defined in the ACM computing curriculum (SIGITE, 2005, p. 24) except that in place of information management our list names hardware support, and in place of human-computer interaction our list names academic work (see Figure 4). Similar to Reichgelt et al. (2004), we have not included HCI (HumanComputer Interaction) as a study path, which might be a controversial issue. However, we take that HCI must not be just a 'path' of its own, but HCI must permeate the whole curriculum. 


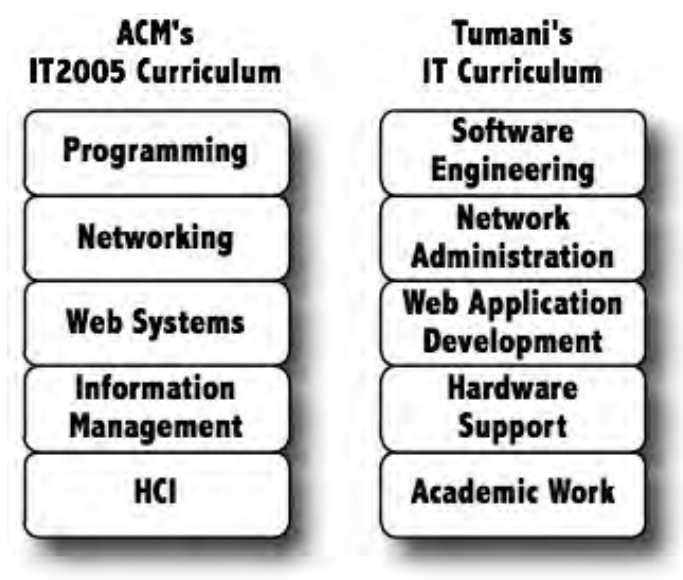

Figure 4: Five Pillars of IT2005 Curriculum and BSC-IT Curriculum

Our five competence paths give students an all-round understanding and skills to work in IT fields in Tanzania. A broad range of skills is necessary because in Tanzania there is a scarcity of IT professionals. For instance, a web developer cannot rely on having a network or hardware specialist at hand if there is a problem with network or hardware.

The five competence paths overlap to some extent. For instance, the Introduction to IT, ICT and Computing course covers some underlying principles of programming as well as some basic hardware topics. Hence, that course belongs both to the programming-oriented software engineering path and to the hardware support path. Similar, the IT Security course is important for network administration competency as well as web developer competency. The BSC-IT program includes 3 credits of elective courses and 6 credits of application projects, which can belong to any of the competency paths in the program.

\section{Five Competence Areas}

The five competence areas in Tumaini's curriculum touch on a number of fundamental topics in the ACM IT curriculum's IT body of knowledge (SIGITE, 2005, p. 19). The software engineering competency track emphasizes programming as well as system integration and architecture. The network administration competency track emphasizes networking as well as information assurance and security. The web developer competency track emphasizes web systems and technologies. The hardware support competency track emphasizes platform technologies as well as system administration and maintenance. The academic competency track emphasizes skills, which are not listed in the ACM IT curriculum's body of knowledge, but which are quintessential for further academic studies or for an academic career. See Table 1 for the emphases of topics in each competency track. 
Table 1: Introduction of the IT Body of Knowledge in Each Competence Track

\begin{tabular}{|l|l|l|l|l|l|l|l|l|l|l|l|l|}
\hline & ITF & HCI & IAS & IM & IPT & NET & PF & PT & SA & SIA & SP & WS \\
\hline Software engineering competency & & & & & & & & & & & & \\
\hline Network admin competency & & & & & & & & & & & \\
\hline Web developer competency & & & & & & & & & & & \\
\hline Hardware support competency & & & & & & & & & & & \\
\hline Academic competency & & & & & & & & & & & & \\
\hline
\end{tabular}

No emphasis

Light emphasis

Medium emphasis

Heavy emphasis

The first row of the table refers to information technology fundamentals (ITF), human-computer interaction (HCI), information assurance and security (IAS), information management (IM), integrative programming \& technologies (IPT), networking (NET), programming fundamentals (PF), platform technologies (PT), system administration and maintenance (SA), system integration and architecture (SIA), social and professional issues (SP), web systems and technologies (WS).

In Table 1, the five competency tracks in Tumaini’s BSC-IT program are listed in the left-hand column, and each of ACM IT curriculum's twelve knowledge areas is on the label row. The table shows how much emphasis of each knowledge area there is in each competence track. The darker the cell color, the stronger a knowledge area in that column is emphasized in the competency track on that row. Although the graduates of BSC-IT program will not be experts in each of these areas, they will have adequate competence for working in each of these fields. Each student can choose his or her elective courses, application project topics, B.Sc. thesis and project topic, as well as internship place according to their own strengths and interests. In Tanzania's IT sector, however, internship places are not very easy to find, so some students are also offered internships at the several campuses of Tumaini University.

Similar to our 'competence areas' concept, Reichgelt, Zhang, and Price (2002) built their IT program on five 'streams' of courses: IT management issues, systems development and support, knowledge management, telecommunications and network administration, and web and multimedia foundations. Reichgelt et al.'s (2002) stream on telecommunications and network administration is somewhat similar to our network administration competency track, and Reichgelt et al.'s stream on web and multimedia foundations is aimed at the same skills as our web developer competency track.

Naturally, while emphasizing some areas of ACM IT curriculum, and while including topics outside ACM IT curriculum, some ACM/IT topics receive less attention in BSC-IT curriculum. Most notably, integrative programming and technologies (IPT, 23 core hours) has been reduced to minimum, many non-core topics have been left out (e.g., social software, firmware, and enterprise deployment software), and some core topics that are not central to Tanzanian IT professions have been left with less attention (e.g., special-purpose databases, emerging technologies, and forensics).

\section{Software engineering competency}

Programming is listed in the ACM IT curriculum as one of the five pillars of IT competency (SIGITE, 2005, p. 24). However, a number of authors argue that the standard computer science sequence in programming education is not necessary for IT students (e.g. Bills \& Biles, 2005). Unlike computer science students, IT students are not required to build large systems from scratch or to handle complex programming tasks (Bills \& Biles, 2005). Rather than writing complete programs from scratch, IT students should have the ability to understand programming lan- 
guages and concepts well enough to be able to write scripts or programs from existing components (Bills \& Biles, 2005).

When the BSC-IT program started for the first time, the course Programming I (Object-Oriented Programming (OOP) and Java) began in the first semester, at the same time with all the other courses. That programming course followed the principles of problem-oriented and practical learning, and students started their programming studies using programming visualization software Jeliot 3 (http://cs.joensuu.fi/ jeliot/). Some difficult issues struck us at once.

The idea for the hands-on programming course was that students would surf the course material using a standard web browser, copy-paste or type some code examples to an editor window, compile and execute the source code to experiment on the program, and save their files for later use (Tedre et al., 2008). However, 89\% of Tumaini's first batch of IT students had never used a computer before coming to the university. When the programming course began, students did not know about surfing, browsers, copying, pasting, typing, code, editors, windows, compiling, executing, saving, programs, or files (or about any other computing concepts for that matter.) Merely working with a computer caused a massive cognitive overhead on top of the cognitive task of learning how to program. Although many students might have been familiar with some of the principles of digital technology, such as syllogistic logic, determinism, and discrete mathematics, few could connect those ideas with their studies.

As the programming courses painfully plowed through, it became crystal clear that either programming courses should be postponed to second semester of the curriculum, or the idea of hands-on, practical learning of programming should be abandoned. We chose the former option and restructured the curriculum so that programming courses begin in the second semester of studies (Tedre et al., 2008).

Programming competency is honed through 13 courses, most of which demand application of programming skills (see Figure 5). Courses on Introduction to IT and Introduction to Digital Logic introduce some basic concepts needed for programming, such as Boolean logic and computer memory. Mathematics for Computer Science and Discrete Structures take students further to the conceptual foundations of computing. Programming is an explicit topic of four courses; two of which are given in Java, one in C, and one is a programming project. Interaction Design is a basic course on HCI. In their final year students undertake programming work in Software Engineering, Advanced Website Development, AI and Robotics, and Data Structures and Algorithms. The number of programming oriented courses may

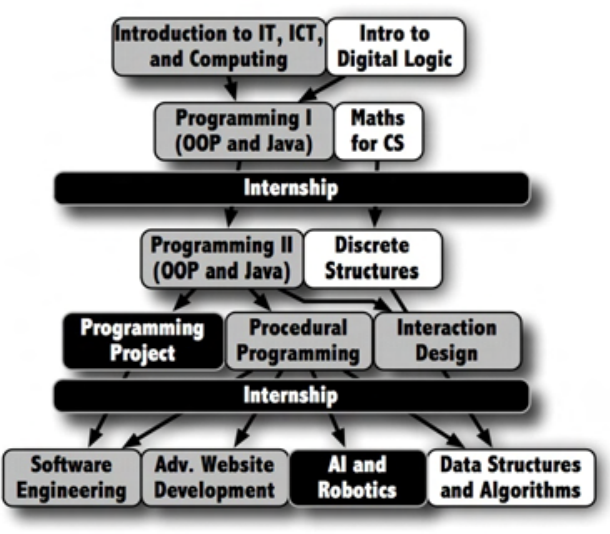

Figure 5: Course Structure in Software Engineering Competency Path seem unnecessary large for an IT program, but those courses prepare the students for M.Sc-level studies in IT as well as computer science.

\section{Network administration competency}

One of the urgent skills needed in the ICT sector in Tanzania is network administration. The country is currently connected exclusively via prohibitively expensive satellite connections, but initiatives like the EASSy submarine cable (http://www.eassy.org), SEACOM submarine cable (http://www.seacom.mu/), or O3B high-speed satellite connection 
(http://www.o3bnetworks.com/), may in a few years time change the face of Tanzania's networking completely. Currently there is no Internet backbone in Tanzania, apart from several companies' own fiber optic cables. There is a high demand of networking professionals, especially wireless networking experts, and the need for those skills is continuously increasing.

The skills needed in Tanzania range from very basic cable-run construction tasks to network design, troubleshooting, and administration. With the exception of government agencies and a few large companies, most network installations in Tanzania-especially in Iringa region-are very small. Common needs include design and implementation of networks, file and printer sharing, setting up and sharing an Internet connection, regulating traffic, managing security settings and updates, managing policies, monitoring and troubleshooting the network, and setting up small servers.

In our program, competency in network administration is built through nine courses (see Figure 6). The track begins with a basic course on web page design and administration and continues to an introductory course, which teaches students some conceptual aspects, such as network topologies, as well as practical aspects, such as making network cables and runs. The course on Network Design and Administration goes into specifics of, e.g., network monitoring tools, user account administration, and sharing printers, files, and the Internet connection. The course on operating systems deals partly with distributed systems. In their final year students have a course on advanced website development, which deals with security issues and other web-related issues, as well as an IT security course, which includes the topic of network security.

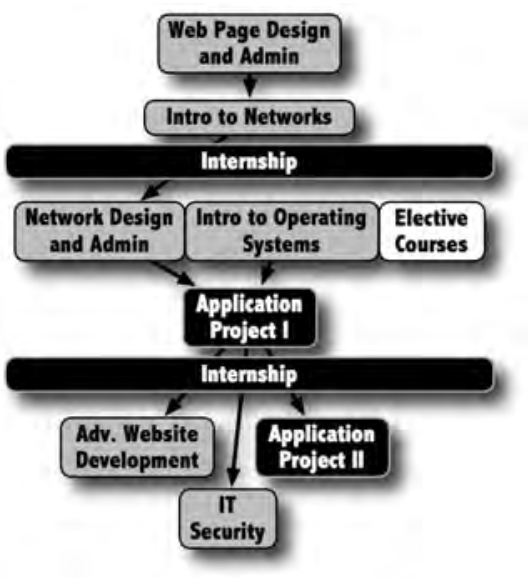

Figure 6: Course Structure in Network Administration Competency Path

\section{Web developer competency}

There has not yet been a significant dotcom boom in Tanzania. It is probable, however, that when the country finally is connected to the rest of the Internet through a submarine cable, and when the Internet charges go down, small and medium enterprises will begin to demand web visibility. Meanwhile, in the industrialized world, the number and variety of web applications is still increasing. Many applications are being designed or re-designed to run on browser platforms. In addition, all kinds of information society development require intensive and extensive utilization of web techniques.

In addition to a lack of competent web developers in Tanzania, there is a scarcity of all kinds of skills related to digital media. Due to lack of good educational programs, there are few skilled people to do multimedia production, video editing, digital imaging, digital sound editing, and all kinds of multimedia work. Although multimedia production skills belong to the toolbox of IT professionals in general, in Tanzania those skills are emphasized.

Web developer competency is built through 12-15 courses, including two courses of communication skills and three optional courses (Figure 7). The courses include two web page design and administration courses, two Java programming courses, a course on database management, a basic human-computer interaction course, courses on multimedia production and image technology, 
a course on e-commerce, and finally an IT security course. Application projects and elective courses can be taken to support the web developer competence area.

\section{Hardware support competency}

Perhaps the most direly needed competency for Tanzanian IT professionals is competency in hardware support. Usually the reason for computers lying around unused is a simple hardware problem. Many of those problems could, however, be easily avoided or fixed with some basic skills and knowledge on computer hardware.

However, there is a marked difference between the skills necessary for building computer installations - such as a networked computer laboratoryin an industrialized country and in Tanzania (e.g.,

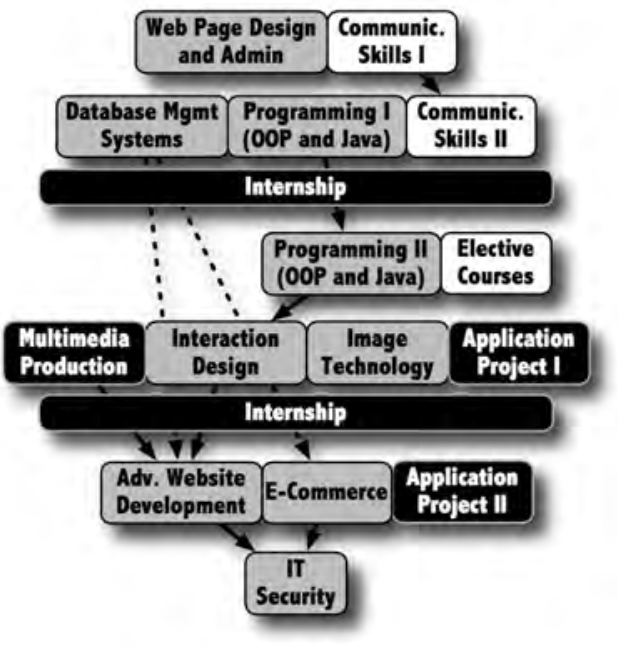

Figure 7: Course Structure in Web Developer Competency Path Kemppainen, 2006). Resources and their availability, climate and environment, as well as organizations, bureaucracy, people, and culture differ greatly between Tanzania and any industrialized country (cf. Kemppainen, 2006). Deficient infrastructure causes problems with, for instance, electricity (brownouts, spikes, power outages) and building reliability (water coming inside in the rainy season, faulty electric wiring, poor materials, poor construction quality, and unsuitable architectural decisions) (e.g. Brewer et al., 2006; Kemppainen, 2006). For instance, when Tumaini University built the university’s first large computer laboratory, the transformer in the public power network could not handle the load and delivered too low voltage (which is potentially damaging for electronics); and it eventually had to be replaced at the expense of the university. Many hardware tools and materials are of the lowest grade quality - for instance, the power drill our colleagues bought for constructing an Internet laboratory started to heat up and smoke after drilling 9 holes; we have experience of RJ45 plugs that do not fit the slots properly or break in a couple of weeks; and we have bought "CAT5e network cable" that does not come even close to the shielding and signal integrity specifications of CAT5e cable. Even more, when acquiring brand name equipment, one can easily go wrong as there are plenty of counterfeit electronic products around, and it takes quite some skill to spot a counterfeit.

Humid, hot, or dusty environment frequently causes electronic equipment to fail (Brewer et al., 2006). In many parts of Tanzania the humidity level is constantly above the specifications for computers and other IT equipment. In the rainy season changes in temperature and humidity are sudden and radical. In most parts of Tanzania room temperatures exceed the working limits of IT equipment. All those environmental issues shorten the life span of computers and other IT equipment. Many environmental issues can be evaded, but one has to be aware of a large number of potential dangers to equipment and people.

In our curriculum, hardware support competency is developed through 5-8 courses, which deal with

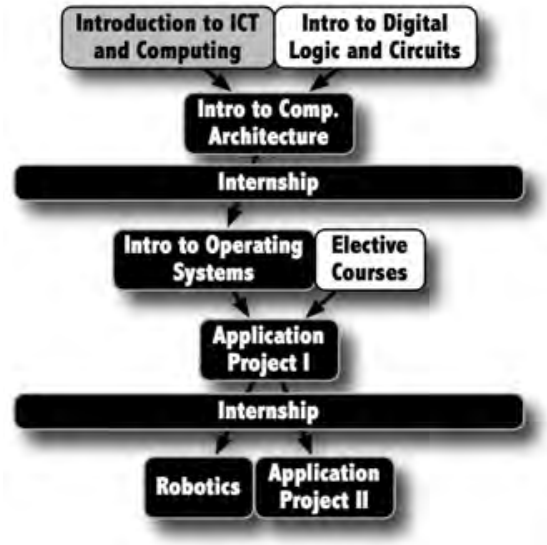

Figure 8: Course Structure in Hardware Support Competency Path 
a broad range of issues ranging from issues of electricity and grounding to installation, troubleshooting, and maintenance of computers and networking equipment (Figure 8). In addition to all those courses, environmental issues and issues of hardware protection are re-visited in a number of other courses, such as network design and administration.

\section{Academic competency}

As described earlier, one of the key principles in Tumaini's BSC-IT program is that it must be internationally recognized. That is, students from that program should be able to pursue further studies in internationally recognized Master's level programs. That is, they must be academically ready for M.Sc. level studies in other programs. To ease comparison between our program and the international standards, all BSC-IT courses are currently being linked with ACM/IEEE curricula (ACM, 2001; SIGITE, 2005) for an easy comparison of course contents.

Researcher training begins already in the first year of studies by two communication skills courses (Figure 9). Those courses focus on developing students' spoken and written skills in academic English. Tumaini University's language of instruction is English, but for many students English is their third language. The native language of many students is their own tribal language like Hehe or Bena; the second language they learnstarting from Standard 1 ( $1^{\text {st }}$ grade $)$ —is Tanzania's official language Swahili, and many have started to learn their third language, English, only in school after Standard 4 ( $4^{\text {th }}$ grade).

In the second semester students take a course on Research Fields of Computer Science, in which they get an idea of the branches of computing disciplines. In their third semester of study, students select an initial topic and begin their work on their B.Sc. thesis project, and that project lasts for two years, until the end of their studies. In addition to the B.Sc. project, in the course of their studies, students have two application projects and two internships, which they can do in any field. B.Sc. thesis topics can be linked with internships, but unlike B.Sc. theses, internships are not graded.

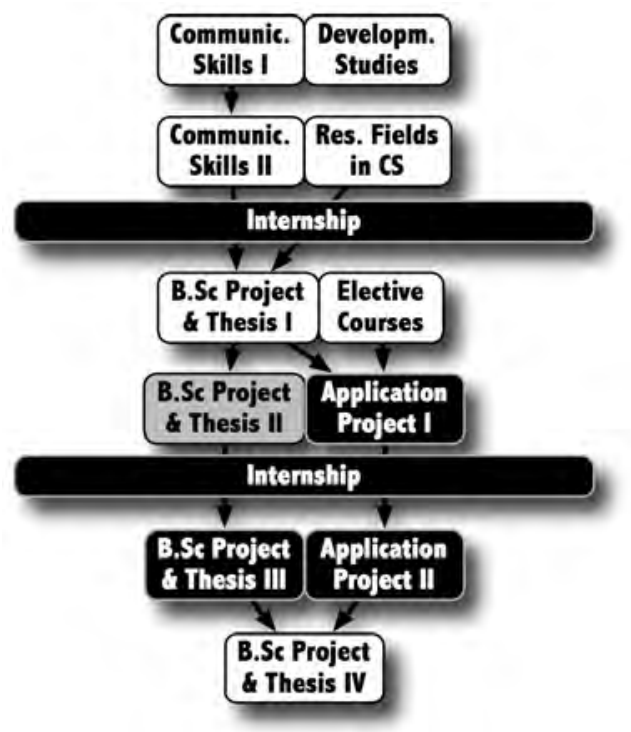

Figure 9: Course Structure in Academic Competency Path

\section{Skill and Responsibility Development}

In addition to the competences that Tumaini's BSC-IT program graduates should have, there are also a number of skills that are important for computing professionals, but that are not taught in any specific course. On top of the core IT skills, described in the Competences section of this article, there are a number of other skills and qualities that an IT professional ought to have. Those skills and qualities include, but are not limited to, teamwork and networking skills; interdisciplinary and innovation skills; leadership and management skills; sustainable planning skills; life-long learning skills; customer service skills; researcher skills; appreciation of law, ethics, moral, and work ethic; and global and social responsibility. We take these skills and responsibilities to be so important that they must be incorporated in the curriculum as threads that run through a number of courses over the three-year program. 


\section{Teamwork and Networking Skills}

Although many tasks in IT professions require intensive and solitary focusing on the task, IT projects are usually carried out in teams. Many IT projects require one to set up a team, organize the roles in the team, and manage the team until the end of the project. Teamwork is not something that people are born with: IT students need to be taught how the roles, mechanics, dynamics, and leadership in teamwork function. The SIGITE Curriculum Committee (2005, p. 28) noted that the value and difficulties of teamwork do not become evident in small-scale projects, and the committee recommended that students should engage in team-oriented projects that extend over a long period of time. In addition, the committee recommended that students should have opportunities to start teamwork early in the curriculum, as well as have a large project that involves a complex implementation task that is done in small student teams, possibly working with an interdisciplinary team.

In the BSC-IT program, students undertake one large project that spans two academic years, during which students work with a business, institution, organization, or individual in Tanzania, in addition to some of the teachers at the BSC-IT program. Each student's task is to work with the stakeholders to identify, analyze, and report a problem; design and implement a solution and test it; and report on the work. In their third semester, students identify a problem that they will focus on, they network with the stakeholders they will have to work with, and begin a literature review on the topic. In their fourth semester, students continue analysis of the problem and start designing a solution. In their fifth semester, students implement and start testing their solution, and in the sixth semester, students finalize testing, evaluate the solution, and finalize their B.Sc. project report.

\section{Interdisciplinary and Innovation Skills}

Environmental conditions and poor availability of materials pose challenges to IT professionals working in Tanzania. Often the work cannot be done following textbook guidelines, but new techniques, methods, or solutions have to be invented on site. Innovation is not only necessary for new techniques and methods, but also for improvements in, for instance, reliability, efficiency, energy consumption, cost-effectiveness, environment-friendliness, and usability of IT services and equipment. Furthermore, innovation is more often than not done by users or customers, and not by manufacturers (von Hippel, 1988), so it is very important to emphasize the importance of listening to end users and nurturing their ideas and thoughts.

Innovation involves creativity, risk taking, and perseverance, and is highly dependent on experimentation (Thomke, 2003). We aim at supporting those qualities of students, but uncertainty avoidance in students, especially in matters of education, has turned out to be unexpectedly high (oddly, the country's uncertainty avoidance index in Hofstede's (1997) model is relatively low). Hence, we have frequently stressed the idea that in technological design there usually is no single 'best' solution, but alternative solutions can be good in different ways. In addition to innovation, interdisciplinarity is necessary for several reasons-for instance, IT professionals' work in different sectors requires readiness to understand people from different disciplines, and knowledge from different disciplines can be effectively used to improve IT work.

\section{Leadership and Management Skills}

As a Bachelor's degree is a relatively high qualification in Tanzania, when Tumaini's students graduate many of them will end up in managerial positions on some level. Those positions require skills in process planning and resource management, in organization and control of human resources, in responsible management of financial assets, in leading and motivating staff, in utilizing technical resources, and in monitoring work. Our students can take elective courses in the 
faculty of business administration and economics: recommended courses include Principles of Management and Financial Management. The third-year course in software engineering includes aspects of management, and teamwork in application courses requires some students to assume the role of team leader.

\section{Sustainable Planning Skills}

In our work with numerous experts from, e.g., Internet service providers, satellite technology companies, uninterruptible power supply firms, software suppliers, thin client system providers, hardware supplies, and many others, we have, to our dismay, come to witness that too often 'solutions' offered by Tanzanian IT professionals are temporary fixes to systemic problems, or patches that may fail again in a short time. Software solutions to our university's needs, which have been proposed to us by consultants or even by large IT companies, have sometimes been outmoded already at the proposal stage. IT-based solutions are major investments for most Tanzanian customers, so it is very important that those solutions have enduring value over a long period of time. We attempt to instill in our students the idea that solutions that have a long life span can be a marketing advantage. The principles of sustainable planning skills are included in practically oriented courses: for instance, when they are designing and building local area networks, our students are required to analyze the life span of those installations and to analyze the risks to the installation.

\section{Life-long Learning Skills}

Life-long learning is both an attitude and a skill. In the field of IT the skills obtained during university education scarcely prepare anyone to work in any field in the industry from day one, and definitely are not enough for a career of four decades. Tanzanian students often have the idea that their education should fully prepare them for their future work; but similar to other countries, the diversity of computing fields and the pace of technological change clearly require students to continue their learning throughout their careers. Students' attitudes towards life-long learning are influenced through introducing role models, providing information about life-long learning, and emphasizing the issue of continuous education in group discussions. The skills and resources required for life-long learning-for instance, e-learning, informal learning, public web fora, and peer-support groups - are all introduced in the course of studies.

\section{Customer Service Skills}

Customer service is an oft-neglected aspect of business in Tanzania. Banks, government offices, many companies, and even consultants often overlook customer service issues. As long as there is no competition, or as long as there is much less supply than demand, businesses can continue to ignore their customers. At some point, however, supply will exceed demand, and customer satisfaction (or lack thereof) will become a serious issue-and those who have invested in customer care will have an advantage over others. It is very important for Tanzanian IT students to develop a professional image as someone working in a service business where customers pay their salary. This issue, if anything, is about influencing the attitudes of students by positive examples.

\section{Research Skills}

Research skills are necessary not only for those who aim at research careers, but for all computing professionals. Research skills do not need to be academic research skills, but a generic set of skills that involve identifying a problem, exploring alternatives, undertaking literature or other kinds of review on the alternatives, designing and carrying out tests, and proposing a solution (Malpas, 2000). In addition, many kinds of problems can be approached in a scientific manner, 
and an ability to approach a problem scientifically—when necessary—is beneficial for computing professionals.

\section{Law, Ethics, Moral, and Work Ethic}

Tanzania's laws regarding electronic mail and electronic evidence (e.g., Tanzania Evidence Act No.6 / 1967) lag behind technological progress. Although there are some legislative amendments that address issues of electronic communication — such as Tanzanian Communications Regulatory Authority Act / 2003 and Electronic and Postal Communications Bill / 2005-there is no single regulatory legal framework for ICT (Mollel, 2008). It is very important that students know the laws and regulations concerning ICT, but due to the incoherent and fragmentary nature of the legal framework concerning ICT in Tanzania, a special course is necessary. Our syllabus includes a course on Cyber Law, which familiarizes students with the most central laws and regulations concerning ICT in Tanzania.

In addition to making the society vulnerable to corruption, fraud, bribery, and abuse of power, deficiencies in the legal frameworks of many developing countries predispose citizens to unethical yet legal actions. Copyright issues are largely unknown, as are trademark and patent issues. Computing ethics is a theme that must pervade the whole curriculum, so students take two dedicated courses in ethics, and themes of computing ethics are linked to other curricular topics.

\section{Environmental Responsibility}

ICT equipment has a relatively short life span and electronic waste is often highly toxic, containing, for instance, lead, mercury, and numerous carcinogenic substances. Used batteries can leak hazardous material, such as mercury and potassium hydroxide, to the environment. ICT equipment's power consumption increases the nation's need for additional power plants. In Tanzania, there is very little knowledge about environmental issues, which leads to neglect of environmental responsibility. The most common methods of waste disposal in rural Tanzania are either to dump the garbage anywhere nearby or to dig a hole in the ground, burn garbage in the hole, and fill the hole. Hence, it is important that students are educated about environmental responsibility throughout their education. It is not easy to achieve a change in attitudes, but we introduce themes of green computing over and over again, especially in hardware-oriented courses. We are also planning a compulsory course on green computing.

\section{Globalization and Social Responsibility}

Tanzania is recognized for her peaceful co-existence of major religions and numerous tribes. Tolerance seems also to be built-in in Tanzanian students. Despite the peaceful co-inhabiting group thinking, tribal thinking, nepotism, and cronyism are, however, often manifest in Tanzanian society: loyalty to one's own group is highly appreciated, and personal relationships often weigh more than competence, skills, degrees, or business sense. Whereas Western students need sometimes to be reminded of global social responsibility and of the hardships of people in the developing world, Tanzanian students need to be sometimes reminded of the inequalities within their own country. When Tumaini's students graduate, they are expected to gain income that greatly exceeds the average income in the country. We emphasize the ethical and social issues of the digital divide within Tanzania, and our students frequently undertake projects in the poorest areas of Tanzania.

\section{Conclusions}

Tumaini University, Iringa University College offers a unique contextualized B.Sc. program in IT. The need for a contextualized approach is not always evident to many Western professionals: 
“Technology is standardized everywhere. Why should not a standard curriculum suffice?” The previous sections covered some of the challenges and prospects that curriculum designers must understand about life and environment in developing countries. In addition, the previous sections described our approach to IT education; an approach that attempts to overcome the challenges in developing countries and to make the most of the prospects of developing countries.

First, pedagogical challenges are unique to each context of IT education. Students have different sociocultural, economic, linguistic, and educational backgrounds, which must be taken into account in all aspects of teaching. In addition, one must understand that imported pedagogical approaches and learning theories that may work very well in one educational setting may fail miserably in another educational setting. The issue of pedagogy-which is the most complex issue in contextualization of IT education-is still open in our program: Currently we employ a problem-based pedagogy, but we continuously try to find alternatives to pedagogy, teaching methods, and student motivation.

Secondly, the desirable level of specialization varies between countries and programs. In many developing countries IT professionals cannot afford a narrow specialization, because there usually is not a large enough competent IT labor force to take care of the other specializations. IT professionals must be able to work as a sort of jack-of-all-trades; they must have a broad knowledge of topics in IT, and they must be able to work with many kinds of basic issues also outside the field of ICT. The scope of knowledge of IT professionals in developing countries goes beyond the confines of IT knowledge. In order to cope with the problems that the rough environment and deficient infrastructure causes, IT professionals must be ready to undertake the basic duties of, for instance, electricians, architects, and carpenters, or otherwise his or her project may be stalled for an indefinite time. Although we cannot teach our students carpentry or architecture, we can encourage them to take initiative when necessary.

Thirdly, the topics that should be emphasized differ between regions and between nations. In a region where tribal thinking is strong, people do not easily move to other regions or countries in order to seek work elsewhere. In a region where ICT infrastructure is underdeveloped, IT professionals must be able to design, build, and maintain infrastructure well. In a region where the closest job opportunities for circuit designers are 2500 miles away, circuit design might not be given centrality in education. Especially if the educational program is aimed at educating people to tackle local issues, curriculum design must be done keeping those local issues in mind.

Fourthly, the cultural, technical, environmental, and other kinds of contextual issues must be understood in curriculum and course design. Standard ACM/IEEE curricula do not even mention environmental and climate issues - in fact, the standard ACM/IEEE IT curriculum does not prepare students to work in rough environments at all. In developing countries IT installations are not built in laboratories and sanitary environments; the environments are often hostile and all aspects of climate conditions can be beyond the equipment specifications. IT projects in developing countries stand or fall by the project members' understanding of and capability to work with local material and technical conditions, environmental conditions, and cultural issues.

Of course, no two developing countries are the same: Some of the issues described in this article may be unique to Iringa, where we work; whereas some other issues may be common to all developing countries. In addition, no cultural, economic, political, or any other kind of context is static: all contextual issues change over the course of time. Nevertheless, one thing about IT education in developing countries is certain: IT education must be based on a deep understanding of the context of education and IT education must respond to the actual needs of each country. Usually that means going beyond the standard IT curricula. 


\section{Acknowledgments}

This research is partially funded by Academy of Finland grant 128577, "Improving the Contextual Impact of ICT Education in Southern Tanzania: Engaging Stakeholders Towards Innovation,” led by Prof. Erkki Sutinen, University of Joensuu, Finland (2009-2012). Our research has also received funding from Kauppaneuvos Otto Malmin Lahjoitusrahasto (2008).

\section{References}

Aasheim, C., Lee, C. K., \& Reichgelt, H. (2006). An implementation of the IT fundamentals knowledge area in an introductory IT course. Journal of Information Technology Education, 5, 373-388. Retrieved from http://jite.org/documents/Vol5/v5p373-388Aasheim129.pdf

ACM Computer Science Curriculum Committee. (2001). Computing curricula 2001: Computer Science.

Backhouse, J. (2005). Learning individual group skills for software analysis and design in Africa. SIGITE '05: Proceedings of the 6th Conference on Information Technology Education, Newark, NJ, USA, 107-112.

Bangu, N., Haapakorpi, R., Lund, H. H., Myller, N., Ngumbuke, F., Sutinen, E., \& Vesisenaho, M. (2007). Information technology degree curriculum in Tanzanian context. In P. Cunningham \& M. Cunningham (Eds.), Proceedings of the IST-Africa 2007 Conference, Maputo, Mozambique, May 9-May 11. CDROM.

Bills, D. P. \& Biles, J. A. (2005). The role of programming in IT. SIGITE '05: Proceedings of the 6th Conference on Information Technology Education, Newark, NJ, USA, 43-49.

Bloom, B. S., Englehart, M., Furst, E., Hill, W., \& Krathwohl, D. (1956). Taxonomy of educational objectives: The classification of educational goals. Handbook I: Cognitive Domain. New York, NY, USA: Longmans.

Brewer, E., Demmer, M., Ho, M., Honicky, R. J., Pal, J., Plauché, M., \& Surana, S. (2006). The challenges of technology research for developing regions. IEEE Pervasive Computing, 5(2), 15-23.

Brooks, F. P., Jr. (1996). The computer scientist as toolsmith II. Communications of the ACM, 39(3), 6168.

Dawson, R. J., \& Newman, I. A. (2002). Empowerment in IT education. Journal of Information Technology Education, 1(2), 125-141. Retrieved from http://jite.org/documents/Vol1/v1n2p125-142.pdf

Denning, P. J., Comer, D. E.; Gries, D., Mulder, M. C., Tucker, A., Turner, A. J., \& Young, P. R. (1989). Computing as a discipline. Communications of the ACM, 32(1), 9-23.

Ekstrom, J. J., Gorka, S., Kamali, R., Lawson, E., Lunt, B., Miller, J., \& Reichgelt, H. (2006). The information technology model curriculum. Journal of Information Technology Education, 5, 343-361. Retrieved from http://jite.org/documents/Vol5/v5p343-361Ekstrom155.pdf

Farrant, J. S. (1981). Principles and practice of education. ( ${ }^{\text {nd }}$ ed.) Longman: UK.

Fielstein, L. \& Phelps, P. (2001). Introduction to teaching: Rewards and realities. Belmont, CA, USA: Wadsworth / Thomson Learning.

Freire, P. (1970). Pedagogy of the oppressed. New York, NY, USA Continuum Publishing Group.

Hamming, R. W. (1969). One man's view of computer science. Journal of the ACM, 16(1), 3-12.

Hofstede, G. (1997). Cultures and organizations: Software of the mind. Intercultural cooperation and its importance for survival. New York, NY, USA: McGraw-Hill.

Islas, C., Vesisenaho, M., Tedre, M., \& Sutinen, E. (2006). Implementing information and communication technology in higher education in Tanzania. In P. Cunningham \& M. Cunningham (Eds.), Proceedings of the IST-Africa 2006 Conference, Pretoria, South Africa, May 3-May 5. CD-ROM. 
ITEA. (2007). Standards for technological literacy: Content for the study of technology (3rd ed.). Reston, Virginia, USA: International Technology Education Association.

Kemppainen, J. (2006). Building ICT facilities for education in a developing country. Analysis of an ICT project at Tumaini University/Iringa University College 2000-2004. Master's Thesis for the Department of Computer Science and Statistics, University of Joensuu, Finland.

Knuth, D. E. (1991). Theory and practice. Theoretical Computer Science, 90, 1-15.

Larsen, E., \& Loft Rasmussen, S. (2008). Social empowerment through ICT education: An empirical analysis of an ICT-educational program in Tanzania. A Master's thesis for the IT-University of Copenhagen.

Lund, H. H., Nielsen, J., Sutinen, E., \& Vesisenaho, M. (2005). In search of the point-of-contact: Contextualized technology refreshes ICT teaching in Tanzania. In Proceedings of the Fifth IEEE International Conference on Advanced Learning Technologies, 2005 (ICALT 2005), July 5-July 8, 983-987.

Malpas, R. (2000). The universe of engineering - A UK perspective. London, UK: The Royal Academy of Engineering. Retrieved March 3, 2008, from http://www.raeng.org.uk/news/publications/list/reports/Universe_of_Engineering.pdf

Mgaya, K. (1994). Development of information technology in Tanzania. In E. P. Drew \& F. G. Foster (Eds.), Information technology in selected countries. Tokyo, Japan: The United Nations University.

Ministry of Communications and Transport. (2003). National information and communications technologies policy. The United Republic of Tanzania, Ministry of Communications and Transport.

Mollel, A. (2008). The legal and regulatory framework for ICT in developing countries: Case study of ICT and the law of evidence in Tanzania. A paper delivered at IPID ICT4D PG/PhD Symposium, September 7-9, 2008.

Reichgelt, H., Lunt, B., Ashford, T., Phelps, A., Slazinski, E., \& Willis, C. (2004). A comparison of baccalaureate programs in information technology with baccalaureate programs in computer science and information systems. Journal of Information Technology Education, 3, 19-34. Retrieved from http://jite.org/documents/Vol3/v3p019-034-098.pdf

Reichgelt, H., Zhang, A., \& Price, B. (2002). Designing an information technology curriculum: The Georgia Southern University experience. Journal of Information Technology Education, 1(4), 213-221. Retrieved from http://jite.org/documents/Vol1/v1n4p213-221.pdf

SIGITE Curriculum Committee. (2005). IT 2005 model curriculum report, October 2005.

Sutinen, E., \& Vesisenaho, M. (2006). Ethnocomputing in Tanzania: Design and analysis of a contextualized ICT course. Research and Practice in Technology Enhanced Learning, 1(3), 239-267.

Tedre, M. (2006). The development of computer science: A sociocultural perspective. Joensuu, Finland: University of Joensuu Press.

Tedre, M. (2008). Computing as engineering. Unpublished manuscript.

Tedre, M., \& Chachage, B. (2008). University students' attitudes towards e-security issues: A survey study in Tumaini University, Tanzania. Paper presented at the 5th International Workshop on Technology for Innovation and Education in Developing Countries, July 31 - August 2, Kampala, Uganda.

Tedre, M., Sutinen, E., Ngumbuke, F. D., \& Bangu, N. (2008). Implementing a contextualized IT curriculum: Ambitions and ambiguities. Presented at the 8th Koli Calling International Conference on Computing Education Research, Lieksa, Finland, November 17-20.

Thomke, S. H. (2003). Experimentation matters: Unlocking the potential of new technologies for innovation. Boston, MA, USA: Harvard Business School Press.

Vesisenaho, M. (2007). Developing university-level introductory ICT education in Tanzania: A contextualized approach. Joensuu, Finland: University of Joensuu Press. 
Vesisenaho, M., Duveskog, M., Laisser, E., \& Sutinen, E. (2006). Designing a contextualized programming course in a Tanzanian University. In Proceedings of the 36th Annual Frontiers in Education Conference, $1-6$.

Vesisenaho, M., Kemppainen, J., Islas Sedano, C., Tedre, M., \& Sutinen, E. (2006). Contextualizing ICT in Africa: The Development of the CATI model in Tanzanian higher education. African Journal of Information and Communication Technology, 2(2), 88-109.

Vincenti, W.G. (1990). What engineers know and how they know it: Analytical studies from aeronautical history. Baltimore / London: The Johns Hopkins University Press.

von Hippel, E. (1988). The sources of innovation. New York / Oxford: Oxford University Press.

\section{Biographies}
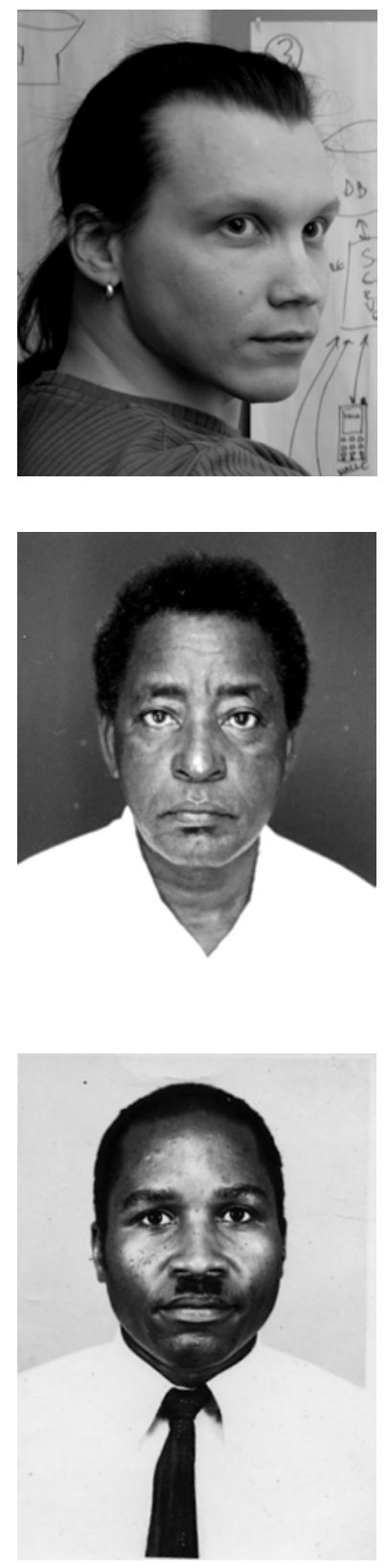

Dr. Matti Tedre works as an associate professor and head of B.Sc. Program in IT at Tumaini University, Tanzania. His research interests include information technology education, ICT for development, social studies of computer science, the history of computer science, and the philosophy of computer science. Previously he has worked and studied at the University of Joensuu in Finland, studied at universities of Ajou and Yonsei in South Korea, worked as a visiting scholar at University of Pretoria in South Africa and Ajou University in South Korea, and worked in the software industry.

Dr. Prof. Nicholas Bangu works as the provost (CEO) of Iringa University College of Tumaini University. Hitherto he taught, researched, and supervised undergraduate and postgraduate students in biochemical studies at the Sokoine University of Agriculture in Tanzania. He has published in refereed journals and proceedings on mostly the cereal grain, sorghum characteristics in relation to its food quality. He has also co-authored a student manual on chemical bonding and molecular structure. In recent years he has taken keen interest in contextualized training of IT for development.

Dr. Prof. Seth I. Nyagava works as deputy provost for academic affairs at Tumaini University, Iringa University College. He holds a $\mathrm{PhD}$ degree in African history and is the author of, for instance, the modern history of the Bena people in Tanzania. His academic work history spans University of Minnesota (U.S.), Northwestern University (U.S.), University of Dar es Salaam (Tanzania), University of Asmara (Eritrea), and Tumaini University. In addition, he has received several grants and fellowships in the U.S. and in Europe and visited several European and American institutions. He is the former head of research and publication at Tumaini University, Iringa University College. Furthermore, he has coordinated several large development projects in Tanzania. 